\title{
EVALUATION OF EXPOSURE PARAMETERS IN PLAIN RADIOGRAPHY: A COMPARATIVE STUDY WITH EUROPEAN GUIDELINES
}

L. Lança ${ }^{1} *$, A. Silva ${ }^{2}$, E. Alves ${ }^{3}$, F. Serranheira ${ }^{1}$ and M. Correia ${ }^{1}$

${ }^{1}$ School of Health Technology, Lisbon Polytechnics, Lisbon, Portugal

${ }^{2}$ Department of Electronic, Telecommunications and Informatics, Aveiro University, Aveiro, Portugal

${ }^{3}$ Nuclear and Technological Institute, Physics Sector, Lisbon, Portugal

Typical distribution of exposure parameters in plain radiography is unknown in Portugal. This study aims to identify exposure parameters that are being used in plain radiography in the Lisbon area and to compare the collected data with European references [Commission of European Communities (CEC) guidelines]. The results show that in four examinations (skull, chest, lumbar spine and pelvis), there is a strong tendency of using exposure times above the European recommendation. The $\mathrm{X}$-ray tube potential values (in $\mathrm{kV}$ ) are below the recommended values from CEC guidelines. This study shows that at a local level (Lisbon region), radiographic practice does not comply with CEC guidelines concerning exposure techniques. Further national/local studies are recommended with the objective to improve exposure optimisation and technical procedures in plain radiography. This study also suggests the need to establish national/local diagnostic reference levels and to proceed to effective measurements for exposure optimisation.

\section{INTRODUCTION}

Patient exposures in diagnostic radiology are increasing at an alarming rate for certain radiographic, fluoroscopic and computed tomography (CT) examinations ${ }^{(1)}$.

According to the UNSCEAR 2000 report, the overall mean effective dose per examination has increased by about $20 \%$ and the annual collective effective dose by nearly $50 \%$, from 1991 to $1996^{(2)}$.

Significant differences in national practices with medical radiation exposure with real impact on population mean annual effective dose are described by several studies ${ }^{(2,3)}$. Reports of wide variations in patient dose for the same radiographic examinations within and among hospitals in the UK and Europe are also described previously ${ }^{(4,5)}$. The following question is addressed in a Special Report ${ }^{(6)}$ : 'Is it really justified for one facility to use an exposure that is 10 , 20 or 126 times greater than that used by another facility to produce a radiographic image?'. In addition, a recent study estimates that the diagnostic use of $\mathrm{X}$ ray causes an increase of cumulative risk of cancer at an age of $75 \mathrm{y}$ : UK $(0.6 \%)$, The Netherlands $(0.7 \%)$, Switzerland $(1 \%)$ and Germany $(1.5 \%)^{(7)}$.

For diagnostic purposes, the optimisation of exposure involves the relationship of three core aspects of the imaging process ${ }^{(8)}$ : (i) choice of radiographic technique; (ii) radiation dose to the patient and (iii) diagnostic quality of the radiographic image. These three aspects are critical for the diagnostic quality of the radiographic image.

*Corresponding author: luis.lanca@estesl.ipl.pt
Exposure parameters influence and determine the quantity and quality of the X-ray beam. The choice of the most adequate radiographic technique to each clinical situation involves the selection of the correct exposure parameters. It is the radiographer's responsibility to adequately select exposure technical parameters except those related to particular equipment characteristics $^{(9)}$.

The four main exposure parameters are tube potential (in $\mathrm{kV}$ ), tube intensity (in $\mathrm{mA}$ ), exposure time (in s) and focus-to-detector distance (in $\mathrm{cm}$ ). Exposure time and tube intensity could be a unique exposure factor (in $\mathrm{mAs}$ ).

In 1996, the Commission of European Communities (CEC) published recommendations concerning Quality Criteria for Diagnostic Radiographic Images ${ }^{(10)}$. These recommendations or Guidelines define diagnostic requirements for a normal, basic radiograph, specifying anatomical image criteria and important image details; indicate criteria for the radiation dose delivered to the patient and give an example for good radiographic technique by which the diagnostic requirements and the dose criteria can be achieved ${ }^{(10)}$.

Several European countries have already incorporated in their national legislation these recommendations and the European directives on radiation protection. In Portugal, the European Directive 97/43/Euratom is already incorporated in Portuguese legislation as well as the European Guidelines recommendations ${ }^{(11)}$.

Although regulation on radiation protection is already incorporated in national legislative documents, in Portugal there is no real implementation of these recommendations in daily clinical practice 


\section{LANÇA ETAL.}

or real established diagnostic reference levels (DRLs). As an example, typical distributions of exposure parameters in plain radiography are unknown in Portugal. This exploratory study could constitute a contribution to the identification of these distributions. We are investigating the typical exposure parameters in plain radiography for skull, chest, lumbar spine and pelvis.

This study aims to identify exposure parameters used in plain radiography in the Lisbon area and to compare collected data with European references ${ }^{(10)}$.

\section{MATERIALS AND METHODS}

A questionnaire was developed and delivered to 85 radiographers working in the Lisbon area, and 35 $(41.1 \%)$ valid responses were returned. They were asked to identify exposure parameters that they are using in their clinical practice for a reference adult patient of $70 \mathrm{~kg}^{(10)}$. Four anatomic regions were considered in seven radiological projections: skull (PA; lateral), chest (PA; lateral), lumbar spine (AP; lateral) and pelvis (AP).

Collected data indicates $\mathrm{kV}, \mathrm{mA}$, exposure time (ms), $\mathrm{mAs}$ and focus-to-detector distance $(\mathrm{cm})$ that are being used in daily practice for each radiological projection.

Data were analysed using the SPSS ${ }^{\circledR}$ version 14.0 statistical software.

\section{RESULTS}

The results shown in this study allow us to identify the main exposure parameters in seven radiological projections in four anatomic regions.

One sample $t$-test at a $95 \%$ confidence interval (CI) of the difference shows a significant deviation $(P<0.001)$ from the test value (Table 1), except for chest lateral. $\mathrm{kV}$ values (mean) for skull PA (63.03), skull lateral (60.11), chest PA (106.08), chest lateral (118.13), lumbar spine AP (66.58) and pelvis AP (66.82) are below the CEC $\mathrm{kV}$ reference values (Test value column). Lumbar spine lateral projection mean $\mathrm{kV}$ value (82.21) is within the recommended interval, although the results show a significant difference $(P<0.001)$ from the lowest $(70 \mathrm{kV})$ and highest $(85 \mathrm{kV})$ reference values.

Table 2 shows that there is no significant deviation from test value for most projections. A significant deviation $(P<0.001)$ is shown for lumbar spine lateral. Mean exposure time values for skull PA (157.01), skull lateral (195.32) and chest PA (21.84) are above the CEC exposure time reference values (Test value column). Chest lateral (33.45), lumbar spine AP (320.14), lumbar spine lateral (466.11) and pelvis AP (287.68) are below the CEC reference level.

Exposure parameters for all projections (tube potential and exposure time) are shown in Figure $1(\mathrm{a}-\mathrm{g})$.
Table 1. Tube potential (in $\mathrm{kV}$ ) one-sample $t$-test at $95 \%$ CI.

\begin{tabular}{lcccrc}
\hline Projection & $\begin{array}{c}\text { Mean } \\
(\mathrm{kV})\end{array}$ & $\begin{array}{c}\text { Standard } \\
\text { deviation }\end{array}$ & $\begin{array}{c}\text { Test } \\
\text { value } \\
(\mathrm{kV})\end{array}$ & $\begin{array}{c}t \text { - } \\
\text { statistic }\end{array}$ & $\begin{array}{c}P \text { - } \\
\text { value }\end{array}$ \\
\hline Skull PA & 63.03 & 6.386 & 70 & -6.732 & $<0.001$ \\
& & & 85 & -21.211 & $<0.001$ \\
Skull & 60.11 & 7.129 & 70 & -8.440 & $<0.001$ \\
lateral & & & 85 & -21.239 & $<0.001$ \\
Chest PA & 106.08 & 18.850 & 125 & -6.188 & $<0.001$ \\
$\begin{array}{l}\text { Chest } \\
\text { lateral }\end{array}$ & 118.13 & 14.114 & & -3.000 & 0.005 \\
$\begin{array}{l}\text { Lumbar } \\
\text { spine AP }\end{array}$ & 66.58 & 6.942 & 75 & -7.274 & $<0.001$ \\
$\begin{array}{l}\text { Lumbar } \\
\text { spine }\end{array}$ & 82.21 & 7.253 & 75 & 6.128 & $<0.001$ \\
lateral & & & 90 & -6.621 & $<0.001$ \\
Pelvis AP & 66.82 & 6.900 & 75 & -7.311 & $<0.001$ \\
& & & 90 & -20.712 & $<0.001$ \\
\hline
\end{tabular}

\section{Table 2. Exposure time (in ms) one-sample $t$-test at $95 \% \mathrm{CI}$.}

\begin{tabular}{lccccc}
\hline Projection & $\begin{array}{c}\text { Mean } \\
(\mathrm{ms})\end{array}$ & $\begin{array}{c}\text { Standard } \\
\text { deviation }\end{array}$ & $\begin{array}{c}\text { Test } \\
\text { value } \\
(\mathrm{ms})\end{array}$ & $\begin{array}{c}t \text { - } \\
\text { statistic }\end{array}$ & $\begin{array}{c}P \text { - } \\
\text { value }\end{array}$ \\
\hline Skull PA & 157.01 & 116.112 & 100 & 1.837 & 0.089 \\
$\begin{array}{l}\text { Skull } \\
\text { lateral }\end{array}$ & 195.32 & 133.106 & & 3.581 & 0.002 \\
$\begin{array}{l}\text { Chest PA } \\
\begin{array}{l}\text { Chest } \\
\text { lateral }\end{array}\end{array}$ & 21.84 & 23.196 & 20 & 0.286 & 0.780 \\
$\begin{array}{l}\text { Lumbar } \\
\text { spine AP }\end{array}$ & 320.14 & 312.528 & 400 & -1.225 & 0.233 \\
$\begin{array}{l}\text { Lumbar } \\
\text { spine }\end{array}$ & 466.11 & 428.648 & 1000 & -5.842 & $<0.001$ \\
$\begin{array}{l}\text { lateral } \\
\text { Pelvis AP }\end{array}$ & 287.68 & 268.652 & 400 & -1.961 & 0.063 \\
\hline
\end{tabular}

Skull observations (Figure 1a and b) are below the CEC recommendation interval for tube potential (76\% PA; $89 \%$ lateral) and above the recommendation for exposure time of $100 \mathrm{~ms}(85 \% \mathrm{PA} ; 80 \%$ lateral).

Exposure parameters for chest radiography are shown in Figure 1c and d. Tube potential results are below the reference of $125 \mathrm{kV}(90 \%$ PA; $62 \%$ lateral). Only a few observations $(23 \%)$ are set on $125 \mathrm{kV}$ or above in lateral projection. Exposure time is below the $20 \mathrm{~ms}(70 \% \mathrm{PA})$ and $40 \mathrm{~ms}(62 \%$ lateral) recommendation. Some results are observed far above the recommended exposure time for both projections. 

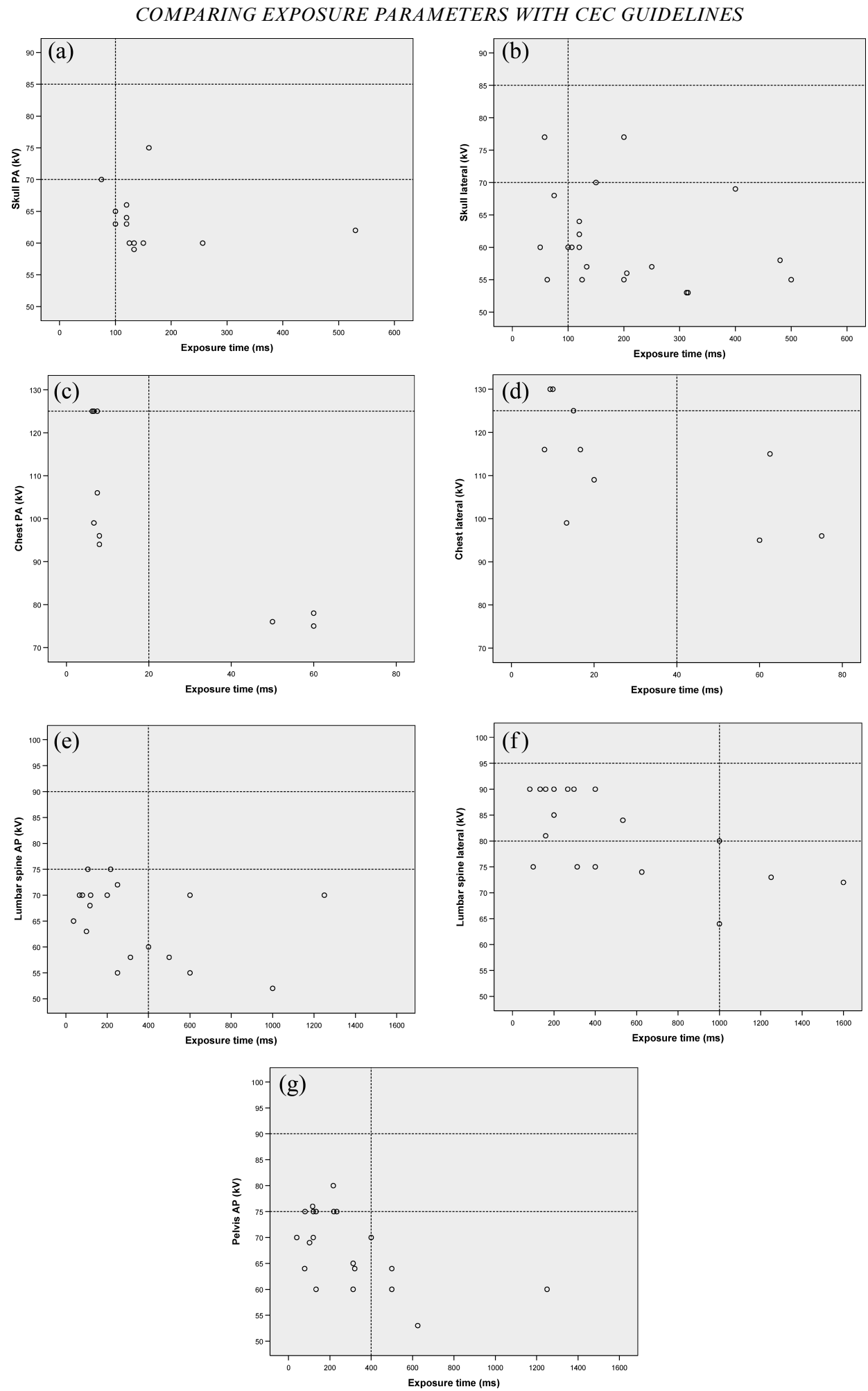

Figure 1. (a-g) Scatter plot showing exposure parameters (tube potential and exposure time).

Page 3 of 5 


\section{LANÇA ET AL.}

Lumbar spine AP projection (Figure 1e) shows $83 \%$ of observations below the reference interval $(75-90 \mathrm{kV})$. In this projection, $30 \%$ of exposure time observations are above the reference of $400 \mathrm{~ms}$. Only $26 \%$ of cases in lumbar spine lateral projection (Figure 1f) are below the reference interval for tube potential and $22 \%$ above the limit of $1000 \mathrm{~ms}$.

Figure $1 \mathrm{~g}$ shows that in $73 \%$ of cases tube potential is below the recommended range of $75-90 \mathrm{kV}$ for pelvis AP projection. Exposure time is $>400 \mathrm{~ms}$ reference in $27 \%$ of cases.

\section{DISCUSSION}

Scatter plots (Figure 1a-g) show a dispersion of exposure parameters without a consistent pattern and a wide variation in exposure parameters for the same radiological projection. A wide dispersion is observed with a predominance of results below the recommended $\mathrm{kV}$ interval and above the recommended exposure time. Compared with CEC guidelines observations show an inadequate selection of exposure parameters. Other studies also demonstrate a wide variation in exposure parameters ${ }^{(12)}$. This could configure a practice of overexposure and collected data suggest that entrance skin dose (ESD) could be above the reference value in several projections since long exposure times are observed in most projections.

The wide variability found in exposure parameters could be explained by differences in equipment characteristics (e.g. screen-film, computed radiography or digital radiography) that is used in the clinical practice by the respondents. Other possible explanations could be the fact that there is a lack of implemented local/national recommendations and lack of criteria for good radiographic techniques in Portugal.

Further actions should be taken to optimise exposure in plain radiography. This study shows tube potential values $(\mathrm{kV})$ systematically below the CEC reference. Literature shows that higher potential values allows considerable dose reduction without loosing image quality. A reduction of up to $29.9 \%$ in patient effective dose was demonstrated in Doherty ${ }^{(13)}$.

It must be mentioned as a possible restriction that collected data are based on personal experience of radiographers. Data were not collected or measured at the time the radiological procedures being carried out. This is important because ESD was not measured or calculated. In some projections, the results show exposure times above the CEC reference level and this could configure a practice of overexposure to the patients.

Implementation of local references could achieve an ESD reduction between 30 and $60 \%$ below the
CEC recommendation ${ }^{(14)}$. Several studies show that it is possible to achieve a dose reduction of $50 \%$ without loosing image quality when CEC guidelines are well established ${ }^{(13,15,16)}$.

\section{CONCLUSIONS}

This study shows that at a local level (Lisbon region) radiographic practice does not comply with CEC guidelines concerning exposure techniques. Further national/local studies are recommended with the objective to improve exposure optimisation and technical procedures in plain radiography. This study also suggests the need to establish national/local DRLs and to proceed to effective measurements for exposure optimisation.

\section{REFERENCES}

1. Seeram, E and Brennan, P. Diagnostic reference levels in radiology. Radiol. Technol. 77, 373-384 (2006).

2. United Nations Scientific Committee on the Effects of Atomic Radiation (UNSCEAR). Sources and effects of ionizing radiation. Annex $D-$ medical radiation exposures (New York: United Nations) (2000).

3. Regulla, D. F. and Eder, H. Patient exposures in medical X-ray imaging in Europe. Radiat. Prot. Dosim. 14, 11-25C (2005).

4. Johnston, D. A. and Brennan, P. C. Reference dose levels for patients undergoing common diagnostic $X$-ray examinations in Irish hospitals. Br. J. Radiol. 73, 396-402 (2000).

5. Carroll, E. M. and Brennan, P. C. Radiation doses for barium enema and barium meal examinations in Ireland: potential diagnostic reference levels. Br. J. Radiol. 76, 393-397 (2003).

6. Gray, J. E. et al. Reference values for diagnostic radiology: application and impact. Radiology 235, 354-358 (2005).

7. Berrington de González, A and Darby, S. Risk of cancer from diagnostic X-rays: estimates for the UK and 14 other countries. Lancet 363, 345-351 (2004).

8. European Commission (EC). Optimisation of protection in the medical uses of radiation. EUR 19793. (Luxembourg: Office for Official Publications of the European Communities) (2002).

9. Bushong, S. C. Radiologic Science for Technologists (St. Louis: Mosby) (2001) ISBN 0-323-01337-6.

10. European Commission (EC). European guidelines on quality criteria for diagnostic radiographic images. EUR 16260. (Luxembourg: Office for Official Publications of the European Communities) (1996).

11. Portugal. Health Ministry - Law no. 180/2002. Establish the rules concerning ionizing radiation protection in medical exposures (8 August 2002).

12. Papadimitriou, D, Perris, A, Molfetas, M. G., Panagiotakis, N, Manetou, A, Tsourouflis, G, Vassileva, J, Chronopoulos, P, Karapanagiotou, O and Kottou, S. Patient dose, image quality and radiographic techniques for common $x$ ray examinations in two Greek 


\section{COMPARING EXPOSURE PARAMETERS WITH CEC GUIDELINES}

hospitals and comparison with European guidelines. Radiat. Prot. Dosim. 95, 43-48 (2001).

13. Doherty, P, O'Leary, D and Brennan, P. C. Do CEC guidelines under-utilise the full potential of increasing $\mathrm{kVp}$ as a dose-reducing tool? Eur. Radiol. 13, 1992-1999 (2003).

14. Vano, E, Fernandez, J. M., Ignacio Tem, J. I., Guibelalde, E, Gonzalez, L and Pedrosa, C. S. A. Real-time measurement and audit of radiation dose to patients undergoing computed radiography. Radiology 225, 283-288 (2002).

15. Mooney, R. and Thomas, P. Dose reduction in a paediatric $X$-ray department following optimization of radiographic technique. Br. J. Radiol. 71, 852-860 (1998).

16. Saure, D., Hagemann, G, and Stender, H.S. Image quality and patient dose in diagnostic radiology. Radiat. Prot. Dosim. 57, 167-170 (1995). 